\section{Management of a complicated buried bumper syndrome with a technique involving dye test, cannulation, and extraction}
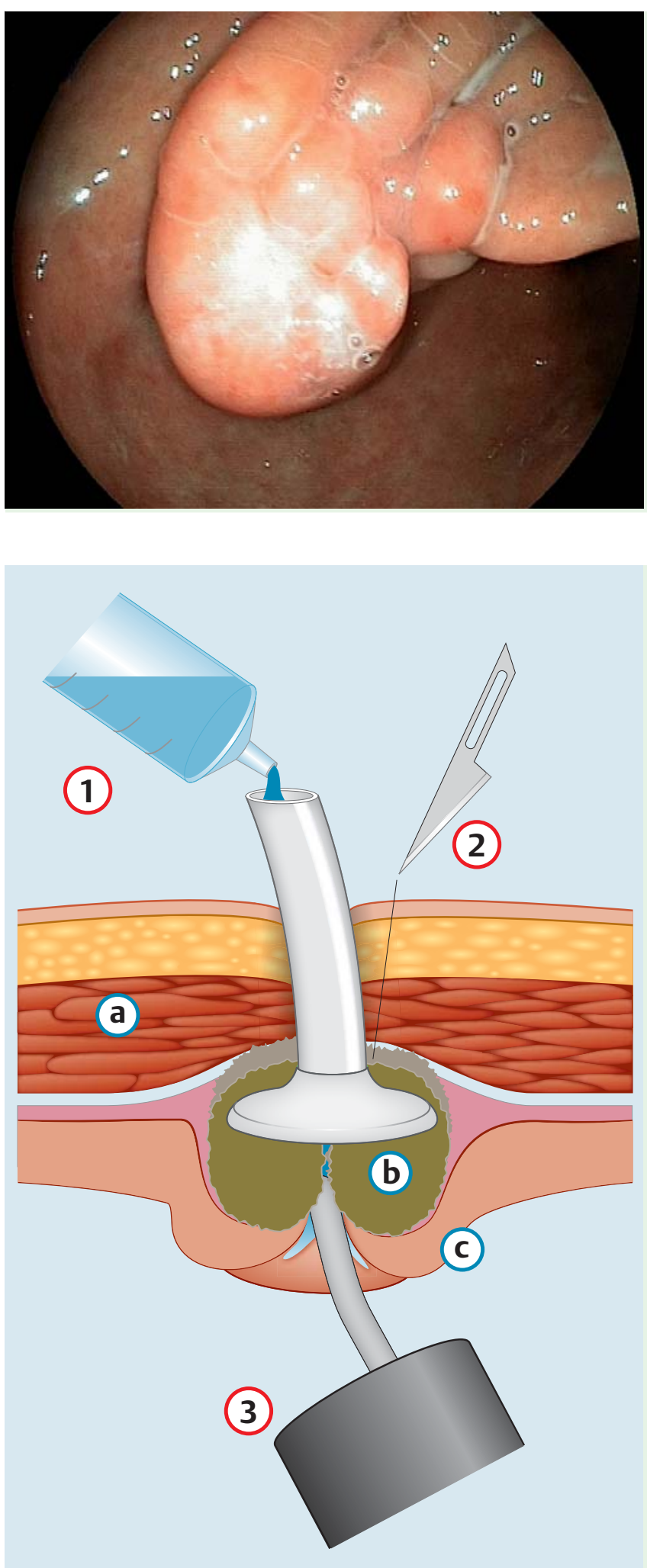

Fig. 1 Endoscopic view of the buried bumper from an 8-year-old occluded percutaneous endoscopic gastrostomy (PEG) tube.

Fig. 2 An illustration of the procedure performed to remove the old percutaneous endoscopic gastrostomy (PEG) tube (a, abdominal wall; $\mathbf{b}$, abscess pouch; c, gastric wall). In step 1, methylene blue dye was injected though the PEG tube. In step 2, an incision was made through the skin and the abscess drained spontaneously on exploration. In step 3, the old PEG tube was cannulated with an endoscopic snare.
An 81-year-old man who had had a percutaneous endoscopic gastrostomy (PEG) tube for 8 years was referred with buried bumper syndrome (BBS) ( $\bullet$ Fig. 1 ). His main complaint was of tube occlusion and his physical examination was normal. The internal orifice of the gastrocutaneous fistula was initially unidentifiable. As illustrated in $\bullet$ Fig. 2, methylene blue was first injected using a constant, steady pressure to identify the internal orifice (step 1). The appearance of the dye took about 30 seconds and allowed the orifice to be clearly identified. Meanwhile drainage from an abscess had been observed at the site of the tract on the skin. A small drainage incision was made and cautious exploration revealed that the abscess pouch was posterior to the abdominal wall. As the abscess cavity was entered, effective drainage occurred spontaneously (step 2).

A snare catheter was advanced through the internal orifice and directly into the lumen of the PEG tube (step 3). The tube was then cut and the guidewire of a new PEG tube was caught with the snare. The old PEG tube was then pulled out and removed. Unsurprisingly the neck of the 8 -year-old tube broke while it was being removed so the bumper remained inside. This situation was ignored and the new PEG tube was placed over the previously placed guidewire. The retained bumper was pushed out on the tip of the new tube ( $\bullet$ Fig.3). The tube was not fixed at this stage and a Penrose drain was placed. The patient commenced feeding 6 hours later and was then sent home. The drain was removed on the second day and the tube was fixed on the third day.

BBS is a complication of PEG that occurs in $2 \%-6.1 \%$ of patients $[1,2]$. Several techniques have been described for the removal of buried bumpers [3]. Among these our description is similar to the "extraction using the tapered tip of a new tube" technique [4]. The difference being that we identified the internal orifice by dye injection.

Blind exploration of the fistula tract and possibly the abscess cavity may be hazardous because contamination of the unprotected abdominal layers may cause serious infection. The use of a technique involving a dye test, cannulation, and then extraction may be beneficial in avoiding such undesired complications.

Endoscopy_UCTN_Code_TTT_1AO_2AK 


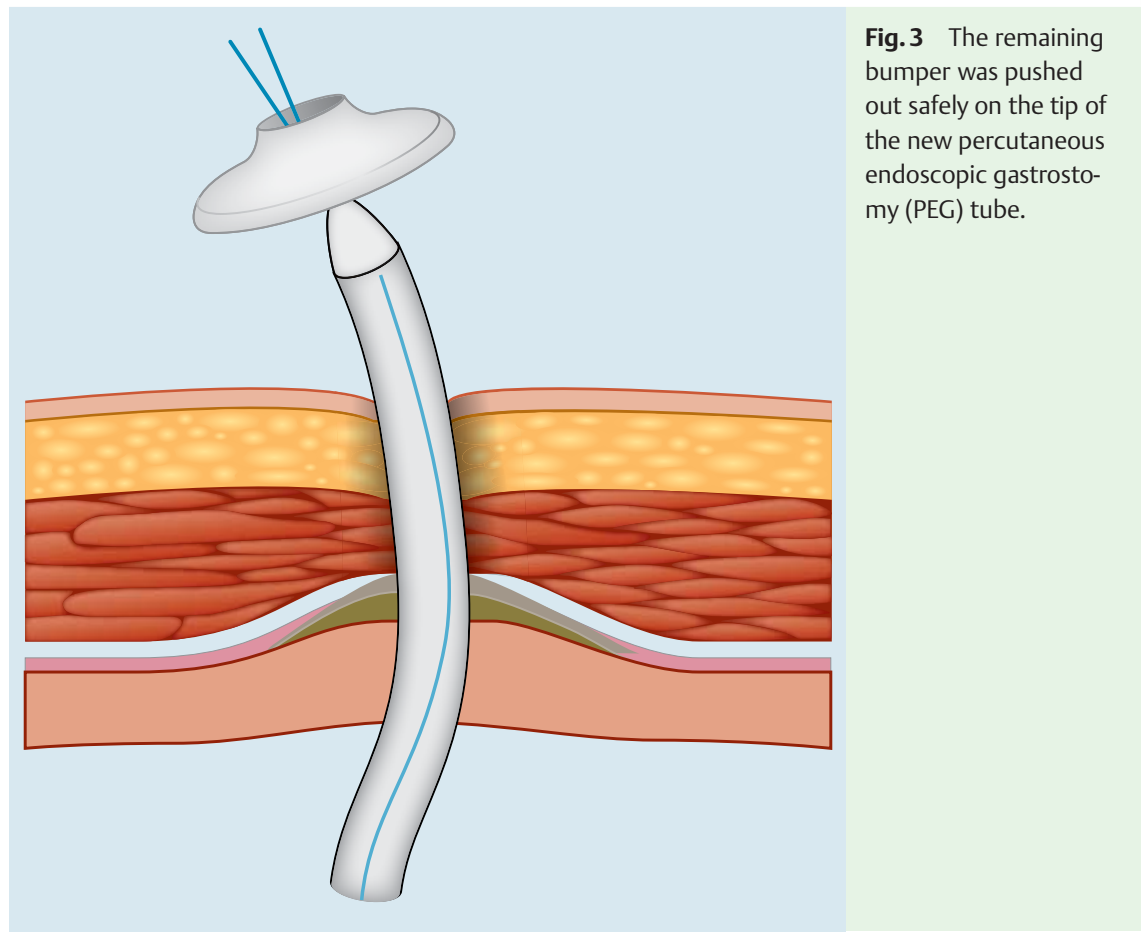

\section{Competing interests: None}

\section{Osman Zekai Öner ${ }^{1}$, Umut Rıza Gündüz' ${ }^{1}$, Ümit Koç ${ }^{1}$, B. R. Karakas ${ }^{1}$, Ferda Akbay Harmandar ${ }^{2}$, Nurullah Bülbüller ${ }^{1}$}

${ }^{1}$ Department of General Surgery, Antalya Training and Research Hospital, Antalya, Turkey

2 Department of Gastroenterology, Antalya Training and Research Hospital, Antalya, Turkey

\section{References}

1 Braden B, Brandstaetter M, Caspary WF et al. Buried bumper syndrome: treatment guided by catheter probe US. Gastrointest Endosc 2003; 57: 747 - 751

2 Ma MM, Semlacher EA, Fedorak RN et al. The buried gastrostomy bumper syndrome: prevention and endoscopic approaches to removal. Gastrointest Endosc 1995; 41: 505 508

3 Strock P, Weber J. Buried bumper syndrome: endoscopic management using a balloon dilator. Endoscopy 2005; 37: 279

4 Venu RP, Brown RD, Pastika BJ et al. The buried bumper syndrome: a simple management approach in two patients. Gastrointest Endosc 2002; 56: 582 - 584

\section{Bibliography}

Dol http://dx.doi.org/ 10.1055/s-0034-1365512 Endoscopy 2014; 46: E238-E239

(c) Georg Thieme Verlag KG Stuttgart · New York ISSN 0013-726X

\section{Corresponding author Osman Zekai Öner, MD}

Department of General Surgery, Antalya Training and Research Hospital Antalya Eğitim Araştırma Hastanesi Varlık Mh.

07050 Muratpaşa/Antalya Turkey

Fax: +90-242-2494462

osmanzekai@gmail.com 